\title{
Recovery Colleges and Dementia Courses - A Scoping Survey
}

\author{
Abstract \\ Purpose
}

This project aimed to understand how dementia is represented within current UK Recovery College courses and how people with dementia are involved with such courses.

\section{Design}

A scoping survey was developed with seven multiple choice questions. Information was collected to find out: How many Colleges are currently offering dementia courses; have previously offered courses or plan to start offering courses; how they have developed their courses; who delivers them; who can attend; and how long they have courses been running.

Individual Recovery Colleges could leave contact details if they were interested in collaborating on future research projects. UK Recovery Colleges were identified using a published list (Anfossi, 2017) supplemented with internet searching. 86 email messages were sent to Recovery Colleges inviting Leads/Managers to complete the survey through an electronic link.

\section{Findings}

Of the 28 (32.6\%) Recovery Colleges who completed the survey, eleven reported to be currently offering dementia courses, with eight planned to start doing so. Six Recovery Colleges stated they were not currently offering dementia courses, have not done so previously and have no current plans to.

\section{Research Implications}

The survey results indicate variability in provision of UK Recovery College courses for people with dementia, and raise further questions about the way the courses are used, their acceptability and usefulness.

\section{Originality}

This service evaluation highlights the variability in what is offered, which is an important step in understanding the current service provision.

Keywords: Dementia; Recovery; Recovery College, service evaluation

Classification of the Article: Research paper (Service evaluation) 


\section{Introduction}

Improved diagnostic routes mean that people are increasingly being given a diagnosis of dementia at an earlier stage in the disease trajectory. The importance of living well with dementia has been highlighted within the UK National Dementia Strategy (Department of Health (DH), 2009), and it is increasingly recognised that supporting the involvement of people in positively managing their illness and their care can raise quality of life (Cheffey et al., 2013).

As the number of older people in the UK population rises, more people are likely to find dementia becoming part of their life: whether they are a person living with dementia, a family supporter or a health care professional working with people with dementia. The Recovery College Model may have the potential to meet some of the needs of people affected by dementia (Perkins, 2016). Yet it seems likely that the specific cognitive impairments associated with dementia such as difficulties with memory, changes in language and planning skills and changes in social behaviours may mean that stakeholders do not see dementia as a condition which fits with the language of personal recovery, or Recovery College delivery in mental health services. In this paper we first draw on literature to illustrate how the concept of personal recovery is highly relevant to people with dementia and how dementia fits within Recovery College ethos, before reporting on a scoping survey undertaken to understand if those affected by dementia can access support through the Recovery College Model across the UK.

\section{Dementia and Recovery}

The social discourse on dementia as an incurable condition leading to a 'living death' seems to be a juxtaposition to the idea of recovery. Yet recovery has been defined as 'a way of living a satisfying, hopeful, and contributing life even with limitations caused by illness' (Anthony, 1993:15); a definition which clearly fits with the English Dementia Declaration (Dementia Action Alliance): that people living with dementia have the right to be recognised as partners in care, provided with education, support, services and training, enabling inclusion within personal communities and positive, proactive support in planning and making life decisions now and for the future.

Five key recovery processes identified by Leamy et al (2011), are described through their conceptual CHIME framework for personal recovery in mental health; (Connectedness; Hope and optimism about the future; Identity; Meaning in life; Empowerment) which is often used to support people in their recovery from mental health problems. The concept of recovery when considered within dementia care has similarities with Kitwood's (1997) conceptual person centred approach in dementia care 
(South London and Maudsley \& South West London and St George's NHS Trusts, 2010; Hill et al, 2010; Irving \& Lakeman, 2010), with both recovery and a person centred approach working towards constructive management of long term conditions in a humanistic way, sharing a common goal, and both focusing on the development of a positive sense of identity, social inclusion, co-working, selfcare and management (Hill et al, 2010). Importantly, both the recovery approach and Kitwood's person-centred approach move from highlighting a person's deficits towards recognising personal strengths (Perkins et al, 2016). McKay et al (2012) suggested that the underlying principles of recovery can be used to generate hope and fulfilment for older people with dementia and suggested that using a person-centred approach to care can also support the meaningful use of recovery principles.

In considering the applicability of recovery principles for people living with dementia, Hammond and Debney (2017) considered in turn the relevance of each of the five CHIME processes of recovery to people with dementia, summarising how concepts can be applied and examining existing literature in this area. For example, the authors highlighted how Daley et al (2013) have reported that maintaining a sense of self is key for recovering life after receiving a diagnosis, a study which demonstrated the applicability of the CHIME process of 'Identity' in people with dementia. Hammond and Debney demonstrated how the difficulties experienced by people with dementia are not unique to this condition and concluded that the concept of recovery can be applicable to all individuals regardless of diagnosis.

In an article exploring whether the concept of recovery is relevant to older people, Woods (2007) highlighted that decisions about the care of a person with dementia are often made quickly, whereas recovery work may need more time. Woods suggested that adopting a recovery approach might allow processes to slow down, giving people more choice and preventing a sense of being overwhelmed by difficulties.

Published evidence about supporting people with dementia by adopting the principles of a recovery model is limited. One research trial identified is reported by Jha et al (2012), who described a small scale randomised controlled trial in which 34 participants completed post-intervention assessments. Jha et al reported that people with dementia who received a recovery-orientated approach and post-diagnostic intervention had greater improvement in wellbeing compared to those who received treatment as usual. 


\section{Recovery Colleges and People with Dementia}

The first Recovery College to be piloted in the UK was in London in 2009, growing to over 75 Recovery Colleges in existence by 2017 in the UK and abroad (Perkins, Meddings, Williams \& Repper, 2018). Meddings et al (2015) summarised that all aspects of Recovery Colleges should encompass co-production, co-facilitation and co-learning. Recovery College courses are co-produced by those with lived experience and those with professional knowledge, varying across locations, with courses taking an educational approach rather than being therapy (Perkins et al, 2018).

In a study exploring whether the students of Sussex Recovery College reflected the demographics of the local and general population, Meddings et al (2019) found the proportion of people aged over 60 accessing the College was lower than would be expected considering the number of people in this age group in the general population. They also reported less people over 70 were accessing the College compared to the proportion of people from this age group accessing mental health services, which they suggested demonstrated an under-representation of older people in Recovery Colleges.

Whilst the Recovery College audience has widened and has been described as including people with dementia (Perkins et al, 2018), extremely limited information exists in the literature on UK Recovery Colleges adopting a recovery approach for people with dementia and offering dementia courses. Whilst locally it is known that xxx Trust (xxx) Recovery College offer a 'Living Well with Dementia' course, the situation in the rest of the UK is largely unknown. A search of the published literature provided information on only two other dementia courses offered through Recovery Colleges, indicating that whilst there may be more courses on offer in the UK, research and evaluation of these to-date is limited.

Perkins et al (2016) suggested that for people with dementia, it has been helpful to offer coproduced and co-delivered courses, referring to four UK Recovery Colleges and providing links to their documents. None of these links are still functioning, and on further internet searches of the four individual Recovery Colleges' prospectuses, only one College appears to be currently offering a dementia course.

Cheffey et al (2017) described the process of co-producing a dementia course for the Devon Recovery Learning Community, highlighting that 'The words of the expert by experience were very powerful... magnified hugely when we worked together to educate and teach' (2017, p.22), with 'the concepts of recovery and personhood were central elements to the delivery of the course' $(2017, p$. 
23), and that 'Recovery orientated practice and co-production can and does work in the context of dementia' (2017, p. 24).

Duff's (2016) poster presentation focused on how recovery principles and Recovery Colleges have been used in work with people with dementia in Lincolnshire. Duff suggested that taking a recovery approach can help to decrease the demands on services and enable people with dementia to have a better quality of life.

Given the limited information about dementia courses published to-date, further projects to understand, evaluate and disseminate information about those courses currently being delivered may develop and support clinical practice across the UK.

\section{Design}

Aims

A scoping survey was developed with the aim of understanding the current practice in UK Recovery Colleges in relation to dementia courses. The objectives were to find out if UK Recovery Colleges are offering dementia courses, and if so, how many do? How are these dementia courses developed, who is involved in this? How are the courses delivered, and who can attend? How long have Colleges been offering dementia courses?

\section{Method}

The survey

A brief scoping survey was developed to gain an understanding of current service delivery. There were eight questions: (1) Does your Recovery College currently run any courses about dementia; (2) Has your Recovery College previously run courses about dementia; (3) Does your Recovery College plan to start running courses about dementia; (4) Who is able to attend these dementia courses; (5) How have you developed your dementia course content; (6) Who are these courses delivered by; (7) How long have these courses been running in your Recovery College? All questions had multiple choice options from which respondents could select all response options that were relevant, as well as space for additional responses to be entered for questions 4, 5 and 6 . Finally, respondents were invited to leave their contact details if they were interested in collaborating on future projects. 
The survey was initially piloted by the local Recovery College Manager to check for coherence, acceptability and that the questions were answerable. At this stage, no further changes to the survey were necessary.

\section{Identifying Recovery Colleges}

The ImROC report 'The current state of Recovery Colleges in the UK: Final report' (Anfossi, 2017) listed 85 UK Recovery Colleges in the appendix. An additional internet search identified a further 16 Recovery Colleges, resulting in a potential sample of 101 Colleges. However, internet searches to find Recovery College contact details indicated that some had either changed their name, were being run by different organisations or had closed, resulting in uncertainty about which details were current. Contact details were identified for 91 of the 101 Recovery Colleges. A standardised email was sent inviting Recovery College Leads/Managers to complete the brief scoping survey. The survey was accessed through a Survey Monkey link embedded in the email. The survey remained open to responses for one month.

Responses to the survey were provided anonymously, unless individual Recovery College Leads/Managers chose to enter their contact details, if they were interested in collaborating on future projects. All responses are reported here anonymously.

This project was classified and approved as a service evaluation by xxx Trust Research and Development Department.

\section{Findings}

Of the 91 emails sent, messages to five Recovery Colleges were undeliverable. Therefore 86 survey invitations were successfully sent, with 28 responses to the survey received, a response rate of $32.6 \%$.

Of the 28 Recovery Colleges who responded, 11 (39.3\% of respondents) reported they are currently offering dementia courses, whilst 17 (60.7\%) are not. Of those 17 not currently running courses, 3 have previously run dementia courses and plan to do so again; 2 have previously run courses but do not have plans to do so again; 5 have never run dementia courses but have plans to start; 6 have never run dementia courses and do not have plans to do so; 1 response was incomplete. 
Eleven Recovery Colleges were delivering dementia courses and these could be attended by people with dementia; family/friends supporting people with dementia; staff working at the NHS Trust; and staff working at another organisation. Additional responses to this question on who could attend were provided by seven respondents: four Recovery Colleges reported being open to anyone/anyone over 18; one to students on placement; one to Peer Support Workers/Volunteers, and one to anyone enrolled at the College.

When asked how they developed their dementia courses, the 11 Recovery Colleges currently delivering dementia courses responded that courses were developed in collaboration with a range of people, but 8 included people living with dementia (see in Table 1). In addition to our offered suggestions, four individual respondents stated they had developed courses in collaboration with partner agencies that specialise in this area; having a representative of the Alzheimer's Society's 'Dementia Friends' network run the course; using a connected dementia support service; working with an author and service user.

Insert table 1 about here

The 11 Recovery Colleges currently delivering dementia courses all responded to question 6, asking who delivers the course. Only 4 of the 11 Colleges reported that people with dementia delivered the course (see Table 2). In addition to our offered suggestions, five respondents also stated that they had developed their individual courses in collaboration with a Representative of 'Dementia Friends'; Peer Support Worker; Peer Trainer; Volunteer from dementia related charity.

Insert Table 2 about here

Out of the 11 Recovery Colleges currently offering dementia courses, five reported these courses had been running for more than 2 years; four Colleges for 1-2 years, and two Colleges for less than a year.

\section{Discussion}

Research Implications

This scoping survey has provided an important insight into the current provision of dementia courses in UK Recovery Colleges, with at least 11 ( $12.8 \%$ of those contacted; $39.3 \%$ of those who responded) offering dementia courses at the time of the survey (May 2019) and an additional eight Recovery Colleges planning to do so. While this suggests an increasing consideration of recovery principles in 
relation to the needs of people with dementia and that people with dementia are included as students of some UK Recovery Colleges, the survey results indicate that the numbers remain low. However, it is possible that some of the Recovery Colleges which did not respond to the survey may also be offering dementia courses and therefore the provision of dementia courses may be greater than reported here.

This evaluation has demonstrated the difficulty inherent in contacting all UK Recovery Colleges and establishing with complete accuracy, the current situation with regards to dementia courses. As with many mental health services, the provision of Recovery Colleges may be in a state of flux.

Importantly the survey results demonstrate variation in provision of Recovery College courses for people with dementia. In part this may be because the application of the recovery concept to people with dementia remains in its infancy, or is perhaps due to the perceived difficulties of co-producing or co-delivering courses alongside people with dementia.

The results of this scoping survey also raise questions about the acceptability and usefulness of dementia courses within Recovery Colleges. Are these courses different or complementary to what may be offered within NHS services? There are also questions about the applicability of dementia courses which are developed by people who do not have dementia.

\section{Originality/Value}

This is the first study exploring the provision of dementia courses by UK Recovery Colleges. The results of this survey represent an important initial step in understanding the current service provision and highlighting the variability in what is currently offered. Further research is needed to gain a more developed understanding of the provision for people with dementia in Recovery Colleges, and importantly the role people with dementia have in the development and delivery of courses.

\section{References}

Alzheimer's Society. Dementia Tax, available at https://www.alzheimers.org.uk/about-us/policy-andinfluencing/what-we-think/dementia-tax (accessed 5.8.2019).

Anfossi, A. (2017), 'The current state of Recovery Colleges in the UK: Final Report'. ImROC: Nottingham 
Anthony, W. (1993), 'Recovery from mental illness: The guiding vision of the mental health service system in the 1990s'. Psychosocial Rehabilitation Journal, 16 (4), 11-23.

Cheffey, J., Hill, L., Roberts, G., and Marlow, R. (2013). Supporting self-management in early dementia: a contribution towards 'living well'? Advances in Psychiatric Treatment, 19, 344-350.

Cheffey, J., Hill, L., McCullough, C., and McCullough, C. (2017), 'Can I facilitate a project when my memory lets me down? The challenges and rewards of co-producing a 'Living Well with Dementia' course'. FPOP Faculty for the Psychology of Older People, 137, 19-26.

Daley, S., Newton, D., Slade, M., Murray, J., and Banerjee, S. (2013), 'Development of a framework for recovery in older people with mental disorder'. International Journal of Geriatric Psychiatry, 28, $522-529$

Dementia Action Alliance, available at https://www.dementiaaction.org.uk/nationaldementiadeclaration (accessed 15.8.2019)

Department of Health (2009). Living Well with Dementia. A National Strategy.

Duff, C. (2016), 'Exploring the use of a recovery college for older people with dementia in the UK'. British Journal of Occupational Therapy, 79, 79.

Hammond, L., and Debney, C. (2017), 'Recovery and dementia: promoting choice and challenging controversy'. Mental Health and Social Inclusion, 21 (5), 297-303.

Hill, L., Roberts, G., Wildgoose, J., Perkins, R., and Hahn, S. (2010), 'Recovery and person-centred care in dementia: common purpose, common practice?' Advances in Psychiatric Treatment, 16, 288298.

Irving, K. and Lakeman, R. (2010), 'Reconciling mental health recovery with screening and early intervention in dementia care'. International Journal of Mental Health Nursing, 19, 402-406.

Jha, A., Jan, F., Gale, T., and Newman, C. (2012), 'Effectiveness of a recovery-orientated psychiatric intervention package on the wellbeing of people with early dementia: a preliminary randomised controlled trial'. International Journal of Geriatric Psychiatry, 28, 589-596.

Kitwood, T. (1997), Dementia Reconsidered. The person comes first. Open University Press Leamy, M., Bird, V., Le Boutillier, C., Williams, J., and Slade, M. (2011), 'Conceptual framework for personal recovery in mental health: systematic review and narrative synthesis'. The British Journal of Psychiatry, 199, 445-452 
McKay, R., McDonald, R., Lie, D., and McGowan, H. (2012), 'Reclaiming the best of the biopsychosocial model of mental health care and 'recovery' for older people through a 'personcentred' approach'. Australas Psychiatry, 20, 492-495

Meddings, S., McGregor, J., Roeg, W., Shepherd, G. (2015). Recovery colleges: quality and outcomes. Mental Health and Social Inclusion, 19: 212-221.

Meddings, S., Walsh, L., Patmore, L., McKenzie, K.L.E., and Homes, S. (2019). To what extent does Sussex Recovery College reflect its community? An equalities and diversity audit. Mental Health and Social Inclusion, 23, 136-144.

Mental Health Foundation (2015). Dementia, rights, and the social model o disability. A new direction for policy and practice? Policy Discussion Paper.

Perkins, R., Hill, L., Daley, S., Chappell, M., and Rennison, J. (2016), 'Continuing to be me - Recovering a life with a Diagnosis of Dementia', Briefing Paper launched at ImROC on 30 September 2016

Perkins, R., Meddings, S., Williams, S., \& Repper, J. (2018), Recovery Colleges 10 Years On. Nottingham: ImROC

South London and Maudsley NHS Foundation Trust and South West London and St George's Mental Health NHS Trust (2010). 'Recovery is for all. Hope, agency and opportunity in psychiatry. A position statement by consultant psychiatrists'. London: SLAM/SWLSTG.

Woods, B. (2007), 'Recovery - is it relevant to older people?' Signposts, 12 (1), 2-3. 
Table 1: Responses to Question 5: How have you developed your dementia course content?

\begin{tabular}{|c|c|}
\hline Multiple Choice Response Option & $\begin{array}{c}\text { Number of Recovery Colleges } \\
\text { selecting this response (\%) }\end{array}$ \\
\hline In collaboration with academic staff & $3(27.3)$ \\
\hline Adopting a course from another site & $3(27.3)$ \\
\hline Using local or national guidelines & $7(63.6)$ \\
\hline Using research publications & $7(63.6)$ \\
\hline In collaboration with people with dementia & $8(72.7)$ \\
\hline In collaboration with NHS staff & $9(81.8)$ \\
\hline Using materials produced by dementia charities & $9(81.8)$ \\
\hline In collaboration with family/friends supporting people with & $10(90.9)$ \\
\hline
\end{tabular}

Table 2: Responses to Question 6: Who are these courses delivered by?

\begin{tabular}{|c|c|}
\hline Multiple Choice Response Option & $\begin{array}{c}\text { Number of Recovery Colleges } \\
\text { selecting this response (\%) }\end{array}$ \\
\hline People with dementia & $4(36.4)$ \\
\hline Staff working at another organisation & $4(36.4)$ \\
\hline $\begin{array}{c}\text { Family/friends supporting people with } \\
\text { dementia }\end{array}$ & $6(54.5)$ \\
\hline Staff working at an NHS Trust & $8(72.7)$ \\
\hline
\end{tabular}

